enable him to help in the maintenance of co-axial cable systems.

In public health, the Assistant Director of the Thailand War Veterans Organization Medical Department is taking a postgraduate course in industrial medicine at the Royal Institute of Public Health and Hygiene, London, and the Surgical Registrar of Pakistan's Liaquat Medical College, Hyderabad, is training in surgery at Guy's Hospital, London. A member of the Physical Medicine and Rehabilitation Department of Siriraj Hospital, Baghdad, is training in occupational therapy at the Occupational Therapy Centre and Training School, London. A medical officer from Nepal is following a postgraduate course in tuberculosis and chest diseases at the Welsh National School of Medicine, Cardiff, and a surgeon from Burma a postgraduate course in the same field at the Birmingham Chest Clinic. Britain is assisting the Institute for Medical
Research at Kuala Lumpur, Malaya, with equipment and has also supplied equipment to the value of $£ 4,700$ to the Technical Training Centre, Moghalpura, Pakistan. Considerable equipment as well as four lecturers have been offered to a Technical Teachers' Training College in West Pakistan, and a Pakistani teacher is taking a twoyear course at the Technical Teachers' Training College, Huddersfield. A lecturer in English was sent to work for two years at the National Centre of Political Adminis. trative and Judicial Studies, Vientiane, Laos. The Chief of the Tariff Section of Thailand's Customs Department is taking a course in general taxation at H.M. Customs and Excise, and trainees from Malaya (1), Pakistan (3), Philippines (2) and Thailand (1) are attending a course of training in central government finance in Britain. Two final chapters deal with co-operation with other agencies and work of the Council and the Bureau.

\title{
NATIONAL STANDARD REFERENCE DATA SYSTEM IN THE UNITED STATES
}

A NATIONAL Standard Reference Data System has been established by the Federal Council for Science and Technology of the United States, and responsibility for its administration has been assigned to the U.S. National Bureau of Standards (National Science Foundation. Scientific Information Notes, 1, No. 4; AugustSeptember, 1963). The System will provide critically evaluated data in the physical sciences on a national basis, centralizing a large part of the present data-compiling activities of a number of Government agencies.

The National Standard Reference Data System will consist of a National Standard Reference Data Centre at the National Bureau of Standards, and various standard reference data centres in other Government agencies and at universities, research institutes and non-Government organizations. For such centres to be a part of the National Standard Reference Data System, they will be required to meet quality standards established by the National Bureau of Standards. However, the independent and operational status of existing critical data projects will be encouraged. The initial emphasis for establishing new standard data compilation projects will be in subject-matter areas where no effort is now being applied or where the existing effort falls far short of meeting important needs for Government, science or industry.

An advisory board will review and recommend policy relative to the operation of the National Standard Data Reference System. It will include, among others, representatives from the U.S. National Academy of Sciences, U.S. National Science Foundation, and federal agencies engaged in research and development.

The National Standard Data Reference System will be conducted as a decentralized operation across the United
States, with central co-ordination by the National Bureau of Standards. As planned at present, the programme will consist of three parts: an input from scientists in many different locations; a central source of the evaluated data at the National Bureau of Standards; and an output system geared to the needs of the nation's scientists and engineers.

The input will come from scientists who are comprehensively reviewing the literature in their fields of specialization and critically evaluating the data for ultimate inclusion in the storehouse of standard reference data. These scientists may be in universities or in industrial or Government laboratories: some will be at the National Bureau of Standards. They will work singly or in small groups oriented to the traditional scientific disciplines. At the same time other scientists, similarly located, will be engaged in experimentally determining the standard reference data which do not exist in the literature. Clearly the interplay between the two groups must be close and continuous.

The central core will consist of the Standard Reference Data Centre at the National Bureau of Standards, where evaluated data will be punched on cards, magnetic tape, in notebooks and other forms, all mechanized for storage and retrieval. A review and control office will label the incoming data as to relative quality and reliability. The Standard Reference Data Centre will classify the data into as many major and minor categories as are required by the needs of the data users.

The output will take the form of a series of services aimed at different technical levels and tailored to the needs of various segments of industry. In general, it will be oriented toward the application of the data rather than toward a field of science.

\section{BIRTH AND DEVELOPMENT OF AN OIL REFINERY}

$\mathrm{T}$ HE Kent Refinery of the British Petroleum Co., Ltd., last year completed its first decade of petroleum refining. In B.P. Magazine No. 9 (1963) there are three articles which vividly describe the conception, siting, construction and evolution of a modern oil refinery, two illustrated in colour, a feature of outstanding artistic merit characteristic of this re-designed 'house-organ' since its inception.

The first of the articles relates to the history of the Isle of Grain on which the refinery is situated, occupying more than 1,200 acres of land bordering the River Medway.
The story traces events from man's occupation of the Island during the late Iron Age (250 B.c.) down to the present time; it is a fascinating epic of reclamation and changing occupation of Medway marsh-land, intimately bound up with the history of the Isles of Grain and Sheppey. The folding pictorial map of this Medway region, in its portrayal of people, industry, shipping and historical events down the centuries, due to Wegner, is quite excellent.

The second article, entitled "A Refinery is Born", attempts to tell the story of the early hopes and fears of 